\title{
Aliança do Pacífico: uma visão do Bloco através do modelo gravitacional
}

\author{
Pablo Chaves Ortiz* \\ André Filipe Zago de Azevedo **
}

\begin{abstract}
Resumo
A partir da década de 1990, houve uma proliferação de Acordos Preferenciais de Comércio (APC) ao redor do mundo. Dentro deste cenário de mudança do comércio mundial, a América Latina foi um importante ator na criação de novos acordos. Entretanto, devido a histórica instabilidade política e econômica da região, nunca houve uma integração completa, devido principalmente ao caráter protecionista dos países. Nesse sentido, a Aliança do Pacífico (Chile, Colômbia, Peru e México) vem com uma proposta de integração econômica diferente, com objetivo de unir suas economias ainda mais e estar aberta às negociações comerciais com terceiros países. O objetivo deste estudo é estimar e comparar o comércio bilateral potencial entre os países membros da Aliança do Pacífico (AP), por meio de um modelo gravitacional de comércio por meio de dados em painel com efeitos fixos para o ano de 2002 e 2013, com uma amostra de 98 países. Os resultados mostraram que o comércio estimado para o ano de 2002 ficou $30 \%$ acima do efetivo, mostrando que havia um comércio potencial a ser explorado. No entanto, em 2013, eles já haviam convergido, com o comércio estimado inclusive ficando 1,2\% abaixo do comércio efetivo. Isso parece demonstrar que a liberalização comercial dos membros da AP, ocorrida antes mesmo de sua formação, contribuiu para que o comércio potencial e o efetivo convergissem.
\end{abstract}

Palavras-chave: Fluxo bilateral de comércio, modelo gravitacional, Aliança do Pacífico.

JEL: F15; F14; C68.

\section{Introdução}

Nas últimas décadas, o mundo tem assistido a uma proliferação de Acordos Preferenciais de Comércio (APC) que tem modificado o cenário econômico internacional. Esse contexto de mudança diz respeito a uma nova onda de regionalismo, diferente daquela ocorrida nas décadas de 1950 e 1960. Nessa época, segundo Prebisch (1949), havia a

\footnotetext{
"Mestre em Economia pela UNISINOS. E-mail: portiz1982@hotmail.com.

***Doutor em Economia pela University of Sussex. Professor do PPGE da UNISINOS e pesquisador do CNPq. E-mail: aazevedo@unisinos.br.
} 
percepção de que as políticas econômicas não atendiam as necessidades de crescimento, portanto os países subdesenvolvidos, principalmente os países da América Latina, não conseguiriam competir em igualdade com os países ricos e precisariam de incentivos especiais para promoção da industrialização interna. Era um regionalismo que não estava de acordo com os preceitos do Acordo Geral de Tarifas e Comércio (GATT).

No novo regionalismo, a partir de 1990, incentiva-se a inserção dos países na economia mundial e a implantação de políticas de atração de investimento com objetivo de promover o desenvolvimento econômico e social de seus integrantes. Sem embargo, a proliferação de acordos bilaterais e multilaterais também é resultado da dificuldade de se fazer avançar as negociações no âmbito da Organização Mundial do Comércio (OMC), pois a criação de um número crescente de barreiras tarifárias e não-tarifárias a fim de proteger o mercado local em detrimento dos bens importados, tem sido feita de forma pouco transparente pelos países. Deste modo, o papel antes exercido por essa organização está sendo substituído por regras regionais negociadas pelos APCs (BHAGWATI; PANAGARIYA, 1996).

Neste contexto, a América Latina foi um importante ator na busca de integração e ampliação de seus mercados com diversos acordos protocolados ao longo do tempo. Entretanto, acordos como a Comunidade Andina (CAN), a Associação Latino-Americana de Integração (ALADI) e o Mercado Comum do Sul (MERCOSUL), por exemplo, não foram capazes de unir o continente (OLIVEIRA, 2014). Portanto, dentro desses esforços de integração na região, a criação da Aliança do Pacífico (AP) poderá ser uma exceção na tumultuada história de associação econômica dos países latinoamericanos. O bloco, formado por Chile, México, Peru e Colômbia em 2012, coincide com o atual momento de expansão dos acordos preferenciais de comércio e num momento importante de inflexão no ambiente econômico internacional.

A AP tem como objetivo criar uma área de livre comércio e aprofundar a integração econômica entre seus integrantes. Uma característica marcante diz respeito ao seu viés econômico mais liberal quando comparado ao vizinho MERCOSUL, principalmente por estarem relativamente integrados entre si e com o comércio mundial, com dezenas de tratados econômicos vigentes e com o objetivo de manter total liberdade nas suas negociações com terceiros países. Como o bloco que está se formando possui um viés mais liberal, fica a dúvida de seu impacto comercial sobre os países participantes. Portanto, este trabalho tem como objetivo estimar e comparar o potencial de comércio bilateral existente entre os países da Aliança do Pacífico para o ano de 2002 e $2013^{1}$, buscando avaliar se ele está acima ou abaixo do comércio efetivo, por meio de um modelo gravitacional.

O modelo gravitacional tem sido amplamente empregado para estimar o comércio potencial entre países, dada a sua capacidade de mensurar as potencialidades de comércio bilateral e estimar a sua evolução ao longo do tempo. O modelo leva em consideração uma série de características (econômicas, geográficas, culturais, etc.) para estimar o co-

${ }^{1}$ Ano mais recente com dados disponíveis.

Econômica-Niterói, v. 20, n. 2, p. 107-134. Dezembro, 2018 
mércio potencial entre pares de países, tornando possível comparar, conforme destacado por Egger (2002), esse comércio potencial com o fluxo de comércio efetivo.

$\mathrm{O}$ artigo está dividido em quatro seções, além desta introdução. Na seção dois é feita uma revisão sobre a formação do bloco e sua atual organização institucional, assim como os acordos bilaterais que os membros participam, além da análise dos fluxos de comércio intra e extrabloco. Na seção 3, é realizada uma revisão teórica e empírica sobre o modelo gravitacional. Na seção quatro, é feita a aplicação do modelo e a análise dos dados sobre o tema abordado, enquanto a seção final apresenta as conclusões.

\section{Aliança do Pacífico: acordos preferenciais e comércio}

A AP constrói um mecanismo de articulação política, econômica e de cooperação e integração recentes formada por Chile, Colômbia, México e Peru, em 2012. Entretanto, sua história começa no final da última década. Segundo Oliveira (2014), o bloco é o resultado concreto do fórum de discussões do Arco do Pacífico, grupo informal implantado em 2007, composto por onze países dos três continentes americanos, banhados pelo Oceano Pacífico como resposta ao novo cenário comercial. Esta iniciativa teria por objetivo não somente impulsionar o livre desenvolvimento e intercâmbio comercial de bens, serviços e investimento entre seus membros, mas serviria como um modelo de integração para a região e como uma plataforma para impulsionar o início das relações comerciais com outros grupos regionais e países do mundo, especialmente com a Ásia e o Pacífico (PÉRES; LARA; GIRALDO, 2013).

Entretanto, ainda que a Declaração de Cartagena de Índias tenha deixado claro, através do acordo adicional sobre a liberação de $92 \%$ dos produtos de forma imediata, os países vinculados a negociação da AP já têm uma tradição integracionista entre eles. Todos os países possuem acordos de complementação econômica no marco da ALADI, assim como tem aprofundado suas relações em busca da liberalização do comércio de maneira bilateral, com exceção de Colômbia e Peru, que já são integrados através da CAN, em conjunto com Bolívia e Equador. Em todos os tratados se negociariam aspectos relacionados aos obstáculos técnicos ao comércio, incluindo temas sanitários, fitossanitários e normas técnicas. Entre os países que menos aprofundaram sua relação bilateral são México e Peru. A posição do México na negociação do TLC com este país foi radicalmente diferente, visto que protegeu em grande parte sua indústria agrícola (GONZALEZ-PEREZ; VIANA; RODRÍGUEZ-RÍOS, 2013).

Na tabela 1, observa-se que Colômbia já goza de acordos bilaterais com cada um dos países negociantes da AP, com uma média de 97\% do universo tarifário desgravado na soma dos três países e com facilidades pactuadas nos regimes sanitários e fitossanitários de cada país. O Chile também possui acordos com os três países com $97 \%$ de desagravo tarifário e com facilidades pactuadas nos regimes sanitários e fitossanitários de cada país. Peru é o terceiro país com mais facilidades negociadas entre os três países, com 92,6\% de 
liberdade tarifária, mais os obstáculos ao comércio. O México é o menos integrado, com uma média de 91,3\% (GONZALEZ-PEREZ; VIANA; RODRÍGUEZ-RÍOS, 2013).

Tabela 1 - Universo tarifário desgravado entre os membros da AP

\begin{tabular}{ccccc}
\hline Pais Outorgante & Colômbia & Chile & Peru & México \\
\hline Colômbia & - & $99 \%$ (TLC) & $100 \%$ (CAN) & $92 \%$ (TLC) \\
Chile & $99 \%$ (TLC) & - & $93 \%$ (ACE) & $99 \%$ (TLC) \\
Peru & $100 \%$ (CAN) & $93 \%$ (ACE) & - & $85 \%$ (TLC) \\
México & $92 \%$ (TLC) & $99 \%$ (TLC) & $83 \%$ (TLC) & - \\
\hline
\end{tabular}

Fonte: Gonzalez-Perez, Viana, Rodríguez-Ríos (2013).

Na década de 1990, o Peru passou a integrar com maior intensidade o comércio internacional ao exportar mais produtos e abrindo seu mercado para importação de outros países. Entre os principais tratados estão a CAN, ALADI e acordos de livre comércio com Chile, China, Canadá, Panamá, Singapura, Coreia do Sul, Costa Rica e, por fim, Associação de Livre Comércio da Europa (Noruega, Suíça, Liechtenstein e Islândia). O país possui acesso preferencial com México e acordos de complementação econômica com a União Europeia e Estados Unidos. O Peru também possui acordo firmado com a Guatemala, mas não em vigência e negocia com Turquia, El Salvador e com a Associação Trans-Pacífico (TPP), tratado de comércio que envolve os países banhados pelo oceano Pacífico (MINCETUR, 2015).

Entre os países do bloco, o Chile se destaca como o mais aberto e o que promove o livre comércio com maior intensidade. Nos últimos dez anos, o Chile tem desenvolvido uma crescente rede de acordos comerciais com países como a Bolívia, Brunei, Canadá, América Central, China, Colômbia, Coreia do Sul, Cuba, Equador, Índia, Islândia, Liechtenstein, MERCOSUL, México, Noruega, Nova Zelândia, Panamá, Peru, Singapura, Suíça, União Europeia e Venezuela. Entre os de maiores destaques estão o acordo de livre comércio com os Estados Unidos e Japão. Neste momento, o país estuda a participação no acordo de livre comércio com a TPP, além de Hong Kong, Tailândia e Indonésia (DIRECON, 2015).

A Colômbia possui acordos de livre comércio com Chile, México, El Salvador, Guatemala, Honduras e com os países da Associação de livre comércio da Europa (Noruega, Suíça, Liechtenstein e Islândia). Também é membro permanente da Comunidade Andina, possui acordos de alcance parcial com a Comunidade Caribenha (CARICON), Venezuela e Nicarágua, acordos comerciais e promoção comercial com os Estados Unidos e a União Europeia e, por fim, tem tratados de complementação econômica com o MERCOSUL e Cuba. Entre os tratados firmados, mas não vigentes estão aqueles com a Coreia do Sul, Costa Rica, Israel e Panamá (MINCOMERCIO, 2015).

No México, o processo de abertura comercial aconteceu de forma mais intensa com a entrada do país no GATT e, posteriormente, na década de 1990, a partir da conclusão das 
negociações com os Estados Unidos e Canadá na criação do Tratado de Livre-Comércio do Atlântico (NAFTA). Desde então, as políticas econômicas e comerciais do país têm se orientado a favorecer o desempenho do país no setor externo. O México conta com una rede de tratados de livre comércio com 45 países, que equivale a praticamente $90 \%$ do comércio exterior deste país. Entre eles estão a Colômbia, Chile, Costa Rica, Nicarágua, Israel, Triângulo do Norte (El Salvador, Guatemala e Honduras) e a Associação de livre comércio da Europa (Noruega, Suíça, Liechtenstein e Islândia). O país também possui 30 Acordos para a Promoção e Proteção Recíproca de Investimentos e 9 acordos de alcance limitado como os Acordos de Complementação Econômica e Acordos de Alcance Parcial com Brasil, Argentina entre outros, no marco da ALADI, além de outros tratados. Não obstante, o México participa ativamente em organismos e foros multilaterais e regionais como o Mecanismo de Cooperação Econômica Ásia-Pacífico (APEC) e a Organização para a Cooperação e Desenvolvimento Econômica (OCDE) (SECRETARIA DE ECONOMÍA, 2015).

\subsection{Comércio na Aliança do Pacífico}

A Aliança do Pacífico é um bloco de integração regional que tem como um dos principais objetivos avançar progressivamente para a livre circulação de bens, serviços, capitais, com o fim de gerar um maior dinamismo nos fluxos comerciais entre os países. A Aliança possuía, em 2014, uma população estimada em 218 milhões de habitantes, um Produto Interno Bruto (PIB) de US\$ 2,19 trilhões e um PIB per capita de US\$ 10.045, considerada a oitava maior economia do planeta, representando aproximadamente $50 \%$ do que a América Latina exportou para o mundo, em 2014 (BANCO MUNDIAL, 2015).

No entanto, os países da AP não possuem uma grande participação no comércio mundial, visto que possuem uma população relativamente pequena, traduzindo-se num mercado consumidor reduzido, com exceção do México. O país mexicano, que possuía uma participação de 1,98\% no comércio mundial, em 2014, tendo um mercado interno consumidor importante estimado em uma população de 122 milhões de habitantes. Este país, membro do NAFTA, direciona 77\% das exportações aos Estados Unidos (BANCO MUNDIAL, 2015).

De acordo com a tabela 2, as exportações da AP em 2013 foram de US\$ 558,1 bilhões, sendo o México o país que mais exportou, registrando US\$ 380 bilhões, valor que representa $68,08 \%$ do total do grupo para o mundo. O Chile, por sua vez, exportou US\$ 77,4 bilhões. Este valor é relativamente alto quando comparado com a Colômbia, terceiro maior exportador, cujas vendas externas somaram apenas US\$ 58,8 bilhões, no mesmo período. México e Chile também são os maiores importadores, com valores de US\$ 381,2 e 79,6 bilhões, respectivamente (UNCTADstat, 2015). O índice de abertura evidencia que Chile e México são os signatários com maior abertura comercial, demonstrando quanto do comércio exterior dos países são representativos em relação ao próprio PIB. Já a Colômbia é o membro em que o índice é o menor entre todos, chegando a $36 \%$. 
Tabela 2 - Indicadores Comerciais da AP (2013)

\begin{tabular}{cccccccc}
\hline País & $\begin{array}{c}\text { Exportaç̃̃es } \\
\text { (bilhões } \\
\text { US\$) }\end{array}$ & $\begin{array}{c}\text { Exportações } \\
\text { (X) \% do } \\
\text { Total }\end{array}$ & $\begin{array}{c}\text { Importações } \\
\text { (bilhões } \\
\text { US\$) }\end{array}$ & $\begin{array}{c}\text { Importações } \\
\text { (X) \% do } \\
\text { Total }\end{array}$ & $\begin{array}{c}\text { Balança } \\
\text { comercial } \\
\text { (bilhões US\$) }\end{array}$ & $\begin{array}{c}\text { Participação } \\
\text { comércio } \\
\text { Mundial }\end{array}$ & $\begin{array}{c}\text { Índice de } \\
\text { abertura } \\
(\text { X+M/PIB) }\end{array}$ \\
\hline Chile & 77,4 & 13,8 & 79,6 & 14,12 & $-2,2$ & 0,44 & 63,41 \\
Colômbia & 58,8 & 10,5 & 59,4 & 10,5 & $-0,55$ & 0,32 & 36,03 \\
México & 380 & 68,08 & 381,2 & 67,63 & $-1,2$ & 1,98 & 66,17 \\
Peru & 41,9 & 7,5 & 43,4 & 7,7 & $-1,5$ & 0,24 & 49,16 \\
\hline
\end{tabular}

Fonte: UNCTADstat, 2015.

Um ponto marcante que caracteriza o bloco, assim como os demais blocos da América Latina, é que ele apresenta baixos níveis de comércio intraregional quando comparado com outros esquemas de integração, como por exemplo, "a União Europeia, onde cerca de dois terços do comércio são realizados dentro das fronteiras do acordo" (CARTA MENSAL INTAL, 2014, p. 9). Nesse sentido, a figura 1 mostra que as importações entre os quatro países são relativamente pequenas quando comparado com o resto do mundo. Ressalta-se que apenas 3,8\% do fluxo bilateral, em média, são provenientes da AP, enquanto $96,2 \%$ é realizado com os demais países. No entanto, a figura também mostra que o comércio intrabloco apresentou crescimento, entre 2004 e 2013, evidenciando um processo, embora suave, de maior integração comercial.

Figura 1 - Percentual de importações AP intrabloco x extrabloco

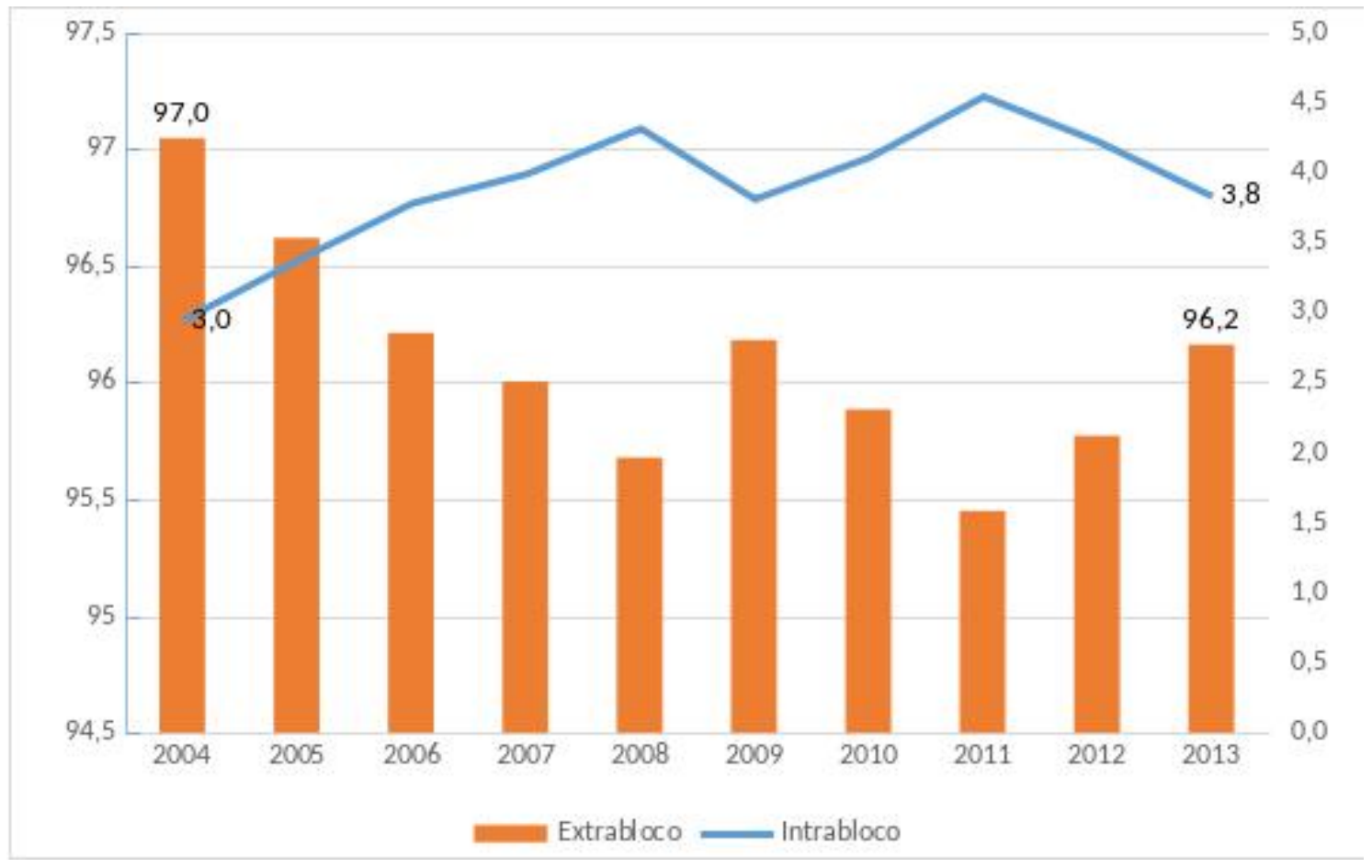

Fonte: UNCTADStat, 2015.

Econômica-Niterói, v. 20, n. 2, p. 107-134. Dezembro, 2018 
A figura 2 apresenta a participação das importações entre os países da AP em relação ao total, no período de 2004 a 2013. O Peru aumentou a participação das importações de US\$ 1,56 para US\$ 4,61 bilhões, entretanto foi o país que teve a maior perda na participação global das importações da AP, saindo de $17,1 \%$ para $11,8 \%$ no total. O México, que importava US\$ 2,19 bilhões do bloco em 2004, aumentou para US\$2,93 bilhões em 2013, mas a participação do bloco também caiu, passando de 1,22\% para apenas $0,78 \%$. Por outro lado, a Colômbia foi o membro da AP que teve o maior aumento na participação das importações da AP. Em 2004, o país transacionava US\$ 1,63 bilhão e este valor aumentou para US $\$ 7,26$ bilhões em 2013, com a participação intrabloco subindo de $11 \%$ para $13,9 \%$, se tornando o país com o maior comércio intrabloco da AP. O Chile aumentou consideravelmente suas importações do bloco, subindo de US\$ 1,66 para US\$ 6,02 bilhões, no período selecionado, mas a participação da AP em relação ao resto do mundo mostrou uma pequena elevação, passando de $7,2 \%$ para $8,2 \%$.

Figura 2 - Participação das importações intra-AP em relação ao total

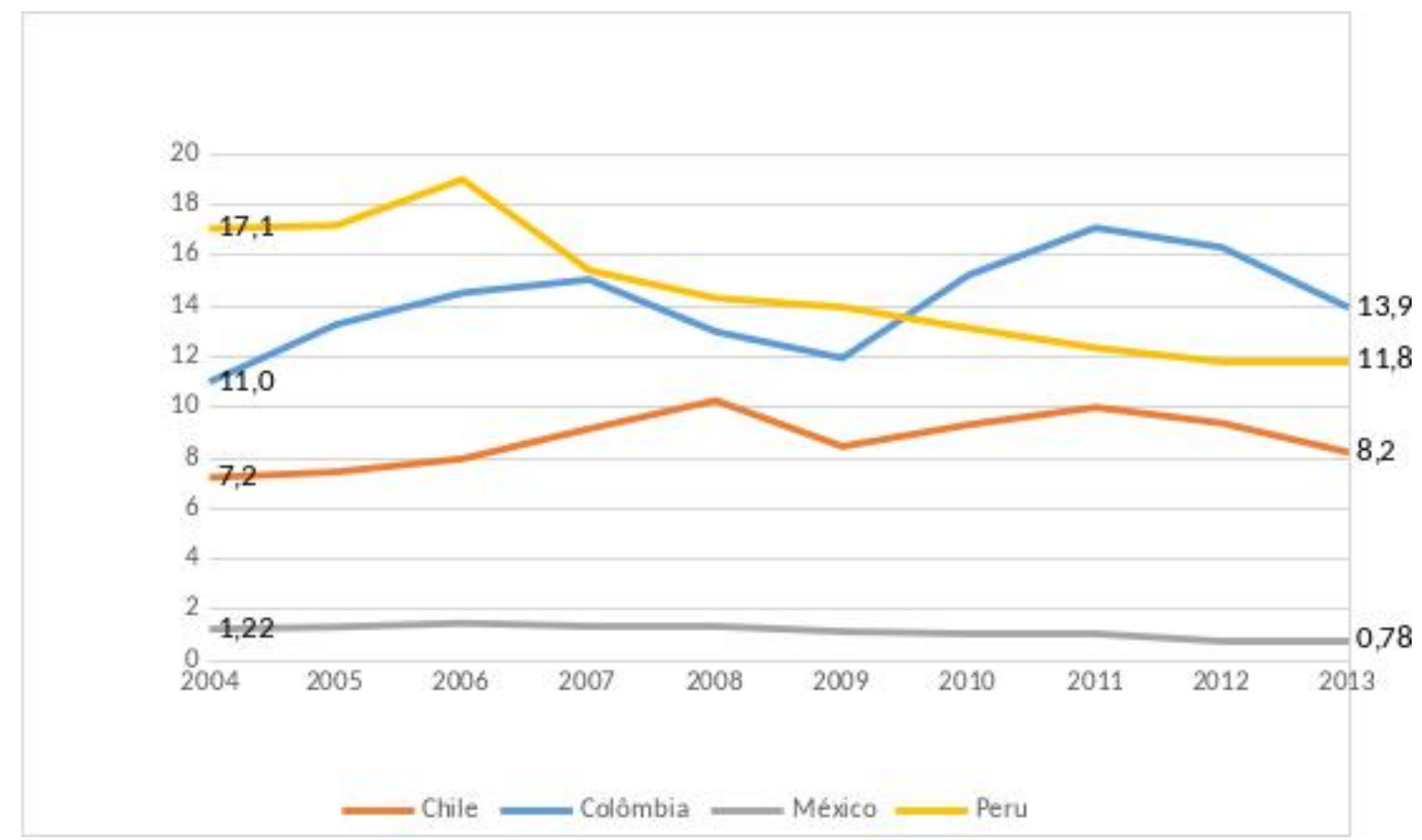

Fonte: UNCTADStat, 2015.

A tabela 3 confirma que o México é o país onde o vínculo comercial com os próprios sócios do acordo é o de menor intensidade, representando apenas $0,8 \%$ de suas importações e $2,3 \%$ de suas exportações totais. O baixo nível de comércio com os demais membros da AP pode sinalizar que há um potencial de comércio a ser explorado. Colômbia e Peru, por outro lado, são os países em que o comércio é de maior intensidade, fato este explicado em parte por serem integrantes da Comunidade Andina. Chile, Colômbia e Peru possuem um volume intrabloco de comércio de 6,2\% nas exportações 
Tabela 3 - Participação da AP nas exportações e importações, 2013

\begin{tabular}{clcccccc}
\hline \multirow{2}{*}{ País/bloco } & & \multicolumn{3}{c}{ Exportações \% } & \multicolumn{3}{c}{ Importações \% } \\
\cline { 3 - 8 } & & AP & MERCOSUL & $\begin{array}{c}\text { Demais } \\
\text { países }\end{array}$ & AP & MERCOSUL & $\begin{array}{c}\text { Demais } \\
\text { países }\end{array}$ \\
\hline \multirow{4}{*}{ AP } & Chile & 5,3 & 8,6 & 86,1 & 8,2 & 14,1 & 77,8 \\
& Colômbia & 6,3 & 7,3 & 86,3 & 13,9 & 8,5 & 77,6 \\
& México & 2,3 & 2,6 & 95,1 & 0,7 & 1,6 & 97,6 \\
& Peru & 7,2 & 6,7 & 86,1 & 11,9 & 10,1 & 78 \\
\hline \multirow{5}{*}{ MERCOSUL } & Argentina & 10,4 & 28 & 61,6 & 5,2 & 28,4 & 66,4 \\
& Brasil & 5,6 & 12,2 & 82,2 & 5,6 & 8,8 & 85,6 \\
& Paraguai & 10 & 45,3 & 44,7 & 2,9 & 42 & 55,1 \\
& Uruguai & 4,6 & 30,7 & 64,7 & 4,3 & 35,6 & 60,1 \\
& Venezuela & 0,9 & 1,9 & 97,2 & 9,2 & 12,1 & 78,8 \\
\hline
\end{tabular}

Fonte: Carta Mensal Intal (2014), adaptado pelo autor.

e $10 \%$ nas importações em média, confirmando a baixa performance comercial. Entretanto, é importante notar que as exportações do Chile, Colômbia e México para os países do MERCOSUL são maiores que as exportações intrabloco, mostrando que os países da AP têm um fluxo comercial maior com o bloco vizinho. O mesmo pode ser visto, mas com menor intensidade nas importações, no Chile e no México, que possuem um fluxo de comércio maior com o MERCOSUL do que com a AP.

Os dados da tabela 4 demonstram que os países do bloco são tradicionalmente exportadores de produtos básicos e de baixo conteúdo tecnológico, concentrando quase $70 \%$ do volume total exportado nestes dois subgrupos. Entre os principais produtos da pauta de exportação de recursos naturais dos países da AP estão os combustíveis, minérios e produtos agrícolas, que refletem as vantagens comparativas da região. Em contraste, fica claro que o México é único dos países da AP que é um grande exportador de bens manufaturados, que se concentram no segmento de média intensidade tecnológica, representando $58,9 \%$ das exportações totais.

Entre as manufaturas que têm certa relevância no comércio intraregional, encontramse as de conteúdo tecnológico médio e as de conteúdo tecnológico baixo, como têxteis, manufaturas de ferro ou aço e plásticos. Deve-se observar que na AP as exportações intrabloco e para o MERCOSUL de setores de média intensidade tecnológica apresentam uma participação em torno de $19 \%$ de bens manufaturados, muito superior à observada com os demais países do mundo, que representam apenas $4 \%$ do total exportado1. Essa maior relevância do comércio de produtos de maior conteúdo tecnológico entre países em desenvolvimento do que na relação comercial com os países desenvolvidos é algo já constatado na literatura. Um dos aspectos importantes da nova onda de regionalismo é justamente o aumento do comércio em desenvolvimento e a alteração de seu perfil, com a presença de manufaturas mais sofisticadas, como destacam Amsden (1987) e Lall (1987).

Econômica-Niterói, v. 20, n. 2, p. 107-134. Dezembro, 2018 
Tabela 4 - AP e MERCOSUL: Composição das exportações segundo conteúdo tecnológico e destino, como \% do total exportado (2013)

\begin{tabular}{llllll}
\hline Origem & Conteúdo Tecnológico & AP & MERCOSUL & Demais países & Total \\
\hline \multirow{4}{*}{ AP (sem México) } & Recursos naturais (primários processados) & 56,3 & 61,3 & 81,2 & 78,1 \\
& Manufaturas de baixo conteúdo tecnológico & 12,2 & 10,9 & 2,5 & 3,8 \\
& Manufaturas de médio conteúdo tecnológico & 20,1 & 18,9 & 3,1 & 5,3 \\
& Manufaturas de alto conteúdo tecnológico & 3,1 & 2,2 & 0,6 & 0,9 \\
& Outros & 8,4 & 6,6 & 12,6 & 11,9 \\
& Total & 100 & 100 & 100 & 100 \\
\hline \multirow{3}{*}{ México } & Recursos naturais (primários processados) & 14,2 & 14,9 & 23,5 & 23 \\
& Manufaturas de baixo conteúdo tecnológico & 12,1 & 7 & 9,1 & 9,1 \\
& Manufaturas de médio conteúdo tecnológico & 58,9 & 64,8 & 45,3 & 46,1 \\
& Manufaturas de alto conteúdo tecnológico & 8,5 & 11,5 & 17,9 & 17,5 \\
& Outros & 6,3 & 1,8 & 4,3 & 4,3 \\
& Total & 100 & 100 & 100 & 100 \\
\hline
\end{tabular}

Fonte: Carta Mensal Intal (2014).

Essa seção mostrou que os membros da AP possuem uma participação significativa em termos de integração comercial na economia mundial, incluindo diversos acordos comerciais entres si, especialmente o Chile. O comércio intrabloco ainda é pouco relevante para os quatro países, sendo praticamente insignificante para o México, mas vem aumentando nos últimos anos. Nesse sentido, é importante examinar se o comércio bilateral dos membros da AP está próximo do seu comércio potencial.

\section{O Modelo Gravitacional de Comércio}

O modelo gravitacional é um método econométrico que tem sido bastante empregado na área de economia internacional. Ele tem sido usado para analisar o impacto de APCs, assim como os efeitos dos fluxos de comércio entre os membros do GATT/OMC, uniões monetárias, impacto dos investimentos direto estrangeiro, inclusive desastres e guerras. O principal benefício de usar o modelo gravitacional de comércio com o objetivo de avaliar os fluxos de comércio de um APC, é que se pode controlar os efeitos de outros determinantes de comércio além dos efeitos de um APC, assim como se pode isolar os efeitos do bloco sobre o comércio (CHEONG; HAMANAKA; PLUMMER, 2010).

Este método é uma analogia ao modelo gravitacional de Newton, em que o comércio entre dois países é diretamente proporcional ao produto de suas rendas e inversamente proporcional a distância entre eles. Em 1962, o trabalho seminal de Tinbergen, um dos primeiros a usar a equação, foi o ponto de partida que deu origem a milhares de publicações e documentos que abrangem uma grande variedade de regiões, períodos de tempo e setores (SHEPERD, 2012). ${ }^{2}$ Segundo Cheong, Hamanaka e Plummer (2010), o exem-

\footnotetext{
${ }^{2}$ Avanços teóricos recentes demonstraram que, longe de ser uma ferramenta puramente econométrica sem uma base teórica (uma crítica precoce contra o modelo de gravidade), modelos gravitacionais poderiam
} 
plo básico de aplicação do modelo gravitacional de comércio, em analogia ao modelo de Newton, relaciona as importações do país $i$ para o país $j\left(M_{i j}\right)$ positivamente com o PIB do país importador $\left(Y_{i}\right)$ e o PIB do país exportador $\left(Y_{j}\right)$, mas negativamente com a distância geográfica entre o país importador e exportador $\left(D_{i} j\right)$.

Segundo Graff e Azevedo (2013), as variáveis PIB e PIB per capita, representam o comércio entre os dois países e servem como uma variável proxy, visto que são propulsoras da demanda por consumo. Nesse sentido, quanto maior forem estes valores, maior é a condição de consumo de seus habitantes e o país importador tende a importar um maior volume de produtos, uma vez que seus habitantes tendem a exigir uma maior variedade de produtos para o consumo. Portanto, para esta variável se espera um valor positivo do coeficiente.

Na variável $D_{i s t} t_{i j}$, existe um efeito negativo, visto que a distância entre as nações gera um fator complicador ao comércio, pelo fato que quanto maior a distância entre os países, maior os custos de transporte, aumentando os preços dos produtos a serem importados, levando os países a terem uma tendência natural de comércio com nações mais próximas, uma vez que a distância pode inviabilizar certas importações (GRAFF; AZEVEDO, 2013). Portanto, a distância entre os países é uma variável que serve como uma proxy, assim como outras variáveis que podem ser incluídas e que capturam os custos de comércio. Os custos de comércio podem ser decompostos em dois tipos: as variáveis naturais e as variáveis não naturais. A primeira se refere àqueles custos de comércio que ocorrem quase que exclusivamente através de barreiras geográficas, tal qual a distância entre um par de países ou se eles falam a mesma língua. As variáveis não naturais ou artificiais referem-se aqueles associados através de medidas político-econômicas, tal como barreiras tarifárias e não tarifárias, por exemplo (BERGSTRAND; EGGER; LARCH, 2013).

Entre as variáveis utilizadas que friccionam o comércio bilateral, também é possível adicionar na equação aqueles países pesquisados que falam a mesma língua, que possuem uma moeda em comum ou que foram colônias no passado, que fazem fronteira, ou que tanto importador quanto exportador são ilhas ou possuem litoral. Ou seja, podem ser introduzidas tantas variáveis históricas como geográfica, além de outras de acordo como o objetivo do pesquisador (CHEONG; HAMANAKA; PLUMMER, 2010). Além disso, estudos mais recentes têm dado ênfase em que o comércio bilateral não é somente uma função da distância entre dois países, mas também da distância do par de países em relação ao resto do mundo. Nesse sentido, quanto maior a resistência multilateral, maior é o comércio bilateral entre o par de países pesquisados (ANDERSON; WINCOOP, 2003).

Soloaga e Winters (2001), com o objetivo de captar os efeitos dos APCs sobre o padrão de comércio, incluíram três dummies na equação gravitacional. Uma dummy que

surgir a partir de uma gama de teorias do comércio. Por exemplo, em trabalho desenvolvido por Bergstrand (1985), o autor demonstrou que um modelo gravitacional pode ser uma implicação direta de um modelo de comércio com base em concorrência monopolística (BANCO MUNDIAL, 2000).

Econômica-Niterói, v. 20, n. 2, p. 107-134. Dezembro, 2018 
serve para medir o grau em que as importações totais dos países do bloco são superiores ao esperado pelo modelo, incluindo os membros do próprio bloco. Outra dummy que computa o grau em que as exportações totais dos membros do bloco são maiores que o esperado, também englobando os países do bloco, e uma dummy intrabloco que captura o comércio entre os membros do bloco que excedem as importações e exportações do bloco.

Sendo assim, um modelo gravitacional de comércio é estimado através de dados de comércio bilateral, PIB, PIB per capita, distância e, possivelmente, de outros determinantes de comércio bilateral incluindo contiguidade (fronteira comum), língua comum etc., utilizando modelos de regressão, tais como o método dos mínimos quadrados, por exemplo, que permite interpretar os coeficientes como elasticidades. A amostra não deve ser restringida apenas aos países pesquisados, mas deve-se incluir a maior quantidade possível de países, visto que uma regressão terá melhor resultados quanto maior for a quantidade possível de informações.

Não obstante, a equação pode ser estimada com dados através de pares de países em relação apenas a um determinado ano (dados de corte ou cross section) ou através de pares de países com observações ao longo de vários anos (dados em painel). Entretanto, os dados em painel são preferíveis em relação aos dados de corte, visto que os efeitos de determinados anos sobre o comércio global podem ser controlados (CHEONG; HAMANAKA; PLUMMER, 2010). Assim, utilizando dados em painel, de acordo com Graff e Azevedo (2013), a equação gravitacional pode ser expressa de forma mais completa na seguinte forma conforme eq. (1):

$$
\begin{aligned}
\ln M_{i j}^{t}=\beta_{0}+\beta_{1} \ln Y_{i}^{t}+\beta_{2} \ln \frac{Y_{i}^{t}}{N_{i}}+\beta_{3} \ln Y_{j}^{t} & +\beta_{4} \ln \frac{Y_{j}^{t}}{N_{j}}+\beta_{5} \ln D i s t_{i j}^{t}+\beta_{6} L_{i j}^{t}+\beta_{7} L_{j i}^{t} \\
& +\beta_{9} I_{j i}^{t}+\beta_{10} M+\beta_{11} M_{i m}^{t}+\beta_{12} M_{e x}^{t}+\varepsilon_{i j}
\end{aligned}
$$

Onde:

- $M_{i j}$ é o comércio bilateral, quer seja em importações ou exportações nominais ou a soma de ambas, do país i para o país $j$;

- $Y_{W}$ é o PIB nominal dos países $i$ e $j$;

- $N_{W}$ é a população dos países $i$ e $j$;

- Dist $t_{i j}$ é a distância entre os países $i$ e $j$;

- $L_{i j}^{t}$ e $L_{j i}^{t}$ são dummies que representam se os países i e j falam a mesma língua;

- $I_{i j}^{t}$ e $I_{j i}^{t}$ são dummies para os países i e j que são uma ilha;

Econômica-Niterói, v. 20, n. 2, p. 107-134. Dezembro, 2018 
- $M$ é a dummy referente ao comércio intrabloco, com a qual se busca avaliar se para os parceiros comerciais, participar de um mesmo bloco econômico influencia no comércio;

- $M_{i m}^{t}$ e $M_{e x}^{t}$ são as dummies referentes às importações e exportações de um país membro do bloco oriundas do resto do mundo, o sinal relativo ao parâmetro desta variável representa uma possível criação ou desvio de comércio;

- Onde t denota o ano das observações;

- $\beta_{0}$ a $\beta_{12}$ são parâmetros de elasticidade que se espera que tenham, à exceção de $\beta_{5}$, sinal positivo; e $\varepsilon_{i j}$ é o erro admitido, com distribuição normal no período $t$.

Por fim, o modelo gravitacional tem sido bastante usado pelos economistas para análise dos fluxos bilaterais de comércio, visto que os dados estão largamente disponíveis, o modelo possui um alto poder de explicação e porque existem diversos trabalhos estabelecidos que facilitam o trabalho dos pesquisadores. Entretanto, o modelo pode produzir resultados viesados se os dados estiverem imprecisos ou se variáveis importantes forem omitidas da estimação.

\subsection{Aplicações do modelo gravitacional para estimação de fluxos bilaterais de co- mércio}

Em geral, os testes empíricos que usaram o modelo de gravidade para estimação do comércio potencial foram bem sucedidos entre os pesquisadores somente a partir da década de 1990. De acordo com Màtyàs (1998), antes desta década, os modelos aplicados a estudos de fluxo bilaterais entre países envolviam basicamente dados em cross-section ou dados de séries temporais para um único país, mas que atribuíam sérias restrições aos modelos aplicados. Segundo Egger (2002), as equações não eram capazes de lidar com o problema da heterogeneidade bilateral do exportador e importador, que é extremamente provável que esteja presente nos fluxos de comércio entre dois países, por exemplo. Entretanto, o aumento no número de estudos sobre o tema propiciou uma melhor fundamentação teórica sobre o modelo, principalmente após o trabalho de Hamilton e Winters (1992).

Estes autores estimaram o fluxo de comércio potencial dos países do leste europeu, a partir da hipótese de abertura econômica com a queda da cortina de ferro, por meio da equação gravitacional. A estimação utilizou dados em cross-section e incorporou variáveis tradicionais como PIB, PIB per capita, distância, adjacência, além de dummies de relações históricas de colonização francesa e inglesa, assim como dummies de preferência comercial com diversos outros blocos econômicos. As estimações foram feitas com 76 países, representando $80 \%$ do comércio global, em um período de três anos (1984 e 1986). Segundo os autores, foi feita uma média dos valores das variáveis dos três anos

Econômica-Niterói, v. 20, n. 2, p. 107-134. Dezembro, 2018 
analisados, visto que eles queriam reduzir efeitos causados por distorções temporárias. A partir de então, os dados estimados pela equação foram comparados com o comércio efetivo. Os resultados do estudo sugeriram que o comércio entre os países da Europa oriental se manteria estável ou até cairia, mas o comércio com os países europeus do ocidente, Estados Unidos e Japão aumentaria entre 5 e 6 vezes.

Soloaga e Winters (2001) aplicaram um modelo gravitacional utilizando dados em painel para 58 países, entre os anos de 1980 a 1996. O objetivo do trabalho era quantificar os efeitos do novo regionalismo no comércio mundial. Nesse sentido, eles modificaram a equação básica do modelo na tentativa de separar os efeitos dos APCs no comércio intrarregional. Apesar do estudo não tratar diretamente sobre a comparação entre comércio estimado e efetivo na formação de blocos econômicos, estas dummies foram importantes como modelo para trabalhos posteriores.

Papazoglou et al (2006) estimaram um modelo gravitacional buscando prever o fluxo de comércio bilateral entre a União Europeia e cada país europeu que não participa do bloco. Ou seja, os autores estimaram o comércio potencial dos países do leste europeu que já passaram da transição de economias socialistas para economias capitalistas maduras ${ }^{3}$, assim como dos principais parceiros comerciais da Europa. A análise se baseou em dados em painel, entre os anos de 1992 a 2003, e comparou os fluxos bilaterais em dois cenários diferentes. Num primeiro momento, estimaram-se os efeitos da entrada dos países do leste europeu no bloco, e logo após, os impactos para os que não aderiram ao bloco. Os autores chegaram à conclusão de que todos os países que se tornassem membros da UE aumentariam seus níveis de comércio interregional, assim tornando as economias mais integradas. Além disso, o comércio iria aumentar entre os países europeus e diminuiria com os países de fora do continente, tal como o comércio com os Estados Unidos.

Papazoglou (2007), por sua vez, estimou o fluxo potencial de comércio da Grécia, tentando explicar se o baixo grau de abertura seria um reflexo da pouca integração comercial do país com a UE, principalmente como resultado do fraco desempenho das exportações de bens do país. A análise estimou dados em painel entre os países da UE e seus principais parceiros comerciais para os anos de 1993, 1998, 2003. Assim, aplicando os coeficientes que determinam os padrões de comércio da União Europeia, foram aplicados na Grécia com o objetivo de estimar o comércio potencial do país. A análise utilizou duas variantes da equação gravitacional. Num primeiro momento, foi aplicada uma equação mais básica, enquanto que num segundo momento, a equação foi expandida para incluir o impacto do comércio intraindústria.

Os resultados demostraram que as exportações gregas reais ficaram abaixo do potencial, enquanto que as importações reais ficaram acima do potencial. Quando o grau de comércio intraindústria é levado em consideração, os resultados também se repetem, mas num nível menor. E, para ambos os casos, a diferença entre as exportações e as

\footnotetext{
${ }^{3}$ Bulgária, República Checa, Estônia, Hungria, Letônia, Lituânia, Polônia, Roménia, Eslováquia e Eslovênia.
} 
importações efetivas em relação à potencial, vem aumentado ao longo dos três anos pesquisados, principalmente em 2003. Segundo o autor, existe diversas explicações para o que vem ocorrendo na Grécia, mas a principal implicação seria que ambos os casos refletem as fragilidades estruturais da economia grega, principal responsável por manter a baixa competitividade dos produtos gregos no mercado internacional.

Graff e Azevedo (2013) estimaram o fluxo potencial de comércio bilateral para os países membros do MERCOSUL, utilizando dados em painel pelo método de efeitos aleatórios. Os dados das importações (variável explicada) e os demais dados são do período de 1999 a 2009, considerando os fluxos bilaterais de comércio de 67 países, acumulando 47.540 observações, com a exclusão dos dados truncados. A amostra representava, no ano de $2009,92,2 \%$ das importações mundiais. Os resultados mostraram uma aproximação considerável de $3,47 \%$ superior ao efetivo entre os valores de comércio potencial total do bloco e o fluxo real de comércio, para o ano de 2009, quando estimados através do método de efeitos aleatórios. Os fluxos que apresentaram maior potencial de comércio foram Argentina e Paraguai e Argentina e Uruguai, enquanto o país que apresentou a maior parte dos fluxos bilaterais potenciais de comércio abaixo do comércio efetivo foi o Brasil.

\section{O comércio potencial da Aliança do Pacífico}

Esta seção tem como objetivo estimar o comércio potencial entre os membros da AP. Para atingir tal objetivo, será aplicado o modelo gravitacional de comércio sobre os fluxos bilaterais de comércio correntes no comércio mundial de produtos. Entretanto, antes será feita a modelagem da equação e explicada a abordagem econométrica.

\subsection{Modelagem da equação}

A metodologia baseia-se em um modelo econométrico capaz de capturar o padrão de comércio mundial. Uma vez estimados tais parâmetros, eles serão usados com o objetivo de criar uma previsão do padrão de comércio dos membros da AP e comparar com o comércio efetivo para o ano de 2013. Em decorrência deste, será possível observar se o potencial de comércio dos países está acima ou abaixo do efetivamente ocorrido.

Para prever o comércio potencial entre os membros do AP, dados geográficos, culturais e dos fluxos bilaterais de comércio entre 98 países da amostra do trabalho foram processados em painel para o período de 12 anos (2002 a 2013), acumulando 98.280 observações, criando uma equação única. A equação gravitacional utilizada neste estudo teve como variável dependente o valor da importação total de mercadorias de cada país da amostra em relação a seus parceiros comerciais, em dólares americanos correntes, obtido junto a UNCTAD. ${ }^{4}$ No total, este estudo compreendeu, em média, 89,8\% das importações

${ }^{4}$ A literatura utiliza o valor das importações, visto que há um maior controle das aduanas sobre tais 
Quadro 1 - Lista de Países da Amostra

\begin{tabular}{|l|l|l|l|l|l|}
\hline África do Sul & Cazaquistão & Iraque & Estônia & Nova Zelândia & Suécia \\
\hline Alemanha & Chile & Irlanda & Filipinas & Omã & Suíça \\
\hline Argélia & China & Israel & Finlândia & Panamá & Tailândia \\
\hline Angola & Colômbia & Itália & França & Paquistão & Taiwan \\
\hline Arábia Saudita & Coreia do Sul & Japão & Gana & Paraguai & Tunísia \\
\hline Argentina & Costa Rica & Jordânia & Grécia & Peru & Turquia \\
\hline Austrália & Croácia & Kuwait & Guatemala & Polônia & Ucrânia \\
\hline Áustria & Cuba & Letônia & Holanda & Portugal & Uruguai \\
\hline Bahrain & Dinamarca & Líbano & Honduras & Quênia & Uzbequistão \\
\hline Bangladesh & Egito & Líbia & Hong Kong & Reino Unido & Venezuela \\
\hline Bélgica & El Salvador & Lituânia & Hungria & República Checa & Vietnam \\
\hline Bielorrússia & Emirados Árabes & Luxemburgo & Índia & República Dominicana & \\
\hline Brasil & Equador & Malásia & Marrocos & Romênia & \\
\hline Bulgária & Eslováquia & Eslovênia & México & Rússia & \\
\hline Canadá & Indonésia & Espanha & Nigéria & Singapura & \\
\hline Catar & Iran & Estados Unidos & Noruega & Sri Lanka & \\
\hline
\end{tabular}

mundiais para o período analisado, segundo dados da UNCTAD (2015), como mostra a tabela 5. Os países da amostra abrangem as maiores economias do globo, representando todas as regiões e incluindo os países da Aliança do Pacífico, como mostra o Quadro 1.

As variáveis independentes que procuram estimar o potencial de comércio dos países são aquelas comumente utilizadas nas equações gravitacionais e estão disponíveis para todos os anos do estudo. As variáveis PIB e PIB per capita, em dólares correntes, são consideradas como proxies para a massa econômica em alusão à equação gravitacional de Newton. Os valores vêm do banco de dados da UNCTAD (2014).

As variáveis distância e distância relativa ${ }^{5}$ entre países estão medidas em quilômetros, enquanto que a área territorial de cada país está medida em quilômetros quadrados. Os dados foram captados da base de dados do Centro de Estudos Prospectivos e de Informações Internacionais (CEPII). A variável adjacência captura o volume do fluxo bilateral de comércio oriundo dos países que possuem fronteiras contiguas. A variável língua captura a relação quando ambos os países falam o mesmo idioma. A variável colonial identifica se os países foram colônias no passado, e a variável litoral captura o comércio quando o país possui litoral. Os dados foram captados através do banco de dados do CEPII e são representadas de forma binária.

Por último, as dummies relativa aos principais APCs foram adicionados às séries de acordo com Soloaga e Winters (2001). Segundo os autores, estas variáveis capturam o fluxo bilateral de comércio quando ambos ou apenas um deles faz parte de um bloco

fluxos (por exemplo, HAMILTON; WINTERS, 1992; GRAFF; AZEVEDO, 2013).

${ }^{5}$ Determinada por fatores físicos, tais como a distância física dos grandes mercados, assim como fatores econômicos, sociais ou políticos. Neste caso a distância relativa é igual a distância dividida pela razão do PIB do país importador e o PIB do país exportador. 
Tabela 5 - Relação das importações da amostra com o resto do mundo (US\$ bilhões)

\begin{tabular}{cccc}
\hline Ano & $\begin{array}{c}\text { Total das importações } \\
\text { da amostra }\end{array}$ & $\begin{array}{c}\text { Importações mundiais } \\
\text { Margem de contribuição }\end{array}$ \\
\hline 2002 & 5.79 & 6.72 & $86,10 \%$ \\
2003 & 7.02 & 7.86 & $89,20 \%$ \\
2004 & 8.57 & 9.57 & $89,50 \%$ \\
2005 & 9.72 & 10.87 & $89,40 \%$ \\
2006 & 11.12 & 12.46 & $89,20 \%$ \\
2007 & 12.96 & 14.33 & $90,40 \%$ \\
2008 & 14.97 & 16.57 & $90,30 \%$ \\
2009 & 11.82 & 12.78 & $92,40 \%$ \\
2010 & 14.07 & 15.51 & $90,70 \%$ \\
2011 & 16.74 & 18.50 & $90,40 \%$ \\
2012 & 16.78 & 18.61 & $90,10 \%$ \\
2013 & 17.00 & 18.90 & $89,90 \%$ \\
\hline
\end{tabular}

Fonte: UNCTADstat (2015).

econômico, tendo em vista que os APCs podem alterar os efeitos líquidos dos fluxos de comércio, adicionando poder explicativo ao modelo. Para os autores citados, foi inserida uma dummy de participação comum em um APC, assumindo valor 1 (um) quando ambos os países do par fazem parte de um mesmo APC e 0 (zero) em outros casos; uma dummy para o importador, com valor 1 (um) quando apenas o importador do par de países é membro de um APC e 0 (zero) caso contrário; uma dummy para o país exportador, com valor 1 (um) quando apenas o exportador do par de países é membro de um APC e 0 (zero) caso contrário. ${ }^{6}$

\subsection{A abordagem econométrica}

A equação gravitacional de comércio final utilizada neste estudo, com fins de estimar o fluxo potencial de comércio dos países da AP foi a seguinte, conforme eq. (2):

$$
\begin{aligned}
& \ln M_{i j}^{t}=\beta_{0}+\beta_{1} \ln Y_{i}^{t}+\beta_{2} \ln \frac{Y_{i}^{t}}{N_{i}}+\beta_{3} \ln Y_{j}^{t}+\beta_{4} \ln \frac{Y_{j}^{t}}{N_{j}}+\beta_{5} \ln D i s t_{i j}^{t}+ \\
& \beta_{6} \ln \text { Distrelat }_{i j}^{t}+\beta_{7} \ln \text { Area }_{i}^{t}+\beta_{8} \ln \text { Area }_{j}^{t}+\beta_{9} \text { Litoral }_{j i}^{t}+ \\
& \beta_{10} \text { Litoral }_{i j}^{t}+\beta_{11} \text { Idioma }_{j i}^{t}+\beta_{12} \text { Colonial }_{j i}^{t}+ \\
& \beta_{13} \text { Adjacencia }{ }_{j i}^{t}+\beta_{14} M+\beta_{15} M_{i m}^{t}+\beta_{16} M_{e x}^{t}+\epsilon_{i j}
\end{aligned}
$$

\footnotetext{
${ }^{6}$ Os APCs que fizeram parte do estudo foram Comunidade Andina, MERCOSUL, ASEAN, NAFTA e União Europeia.
}

Econômica-Niterói, v. 20, n. 2, p. 107-134. Dezembro, 2018 
Na equação gravitacional, todas as variáveis, com exceção das dummies, foram transformadas para a forma log-linear, visto que a variável independente é estritamente positiva, aliviando e até mesmo eliminando o problema de uma distribuição heteroscedástica ou concentrada, assim como tornando as estimativas menos sensíveis a outliers e mais fáceis de interpretar, visto que estarão expressas em termos de elasticidades, conforme sugerido por Reis et al (2014). Também foi verificada a quantidade de dados zerados da variável dependente, que equivale a apenas 3,45\% da amostra de 3.397 observações,. Neste sentido, optou-se por excluir essas observações devido ao risco de enviesar as estimativas, visto que o log de um número pequeno é um número negativo alto.

Retirada as observações zeradas da amostra e os dados transformados para forma loglinear, foi estimada uma regressão linear única através de dados em painel, pelo método dos mínimos quadrados ordinários, tanto pelo método de efeitos fixos quanto pelo de efeitos aleatórios, mantendo-se apenas os dados com coeficientes significativos. No total, foram utilizadas 28 variáveis para a estimação.

Uma vez realizada as estimações, identificou-se o método mais adequado para este estudo. Uma forma de avaliar qual deles é o mais apropriado na estimação entre um modelo linear de dados em painel de efeitos aleatórios ou fixos é o teste de Hausman. Segundo Cameron e Trivedi (2009), sob a hipótese nula de que os efeitos individuais são aleatórios, o teste de Hausman verifica se os estimadores são similares (efeitos aleatórios) ou se divergem entre si (efeitos fixos) para cada indivíduo. Neste momento é importante saber se os estimadores que influenciam o comportamento da variável dependente entre os países também divergem entre países (efeitos fixos).

Neste estudo efetivo do bloco, a aplicação do teste auxilia na rejeição da hipótese nula de que o modelo de efeitos aleatórios oferece estimativas dos parâmetros mais consistentes, de modo que, neste caso $X^{2}=1658.52$, Prob $>$ chi2 $=0.0000$. Sendo assim, o teste indicou que o método de efeitos fixos se apresenta como o mais eficiente. Entretanto, as duas equações foram testadas na comparação entre o comércio estimado e o efetivo, com o método de efeitos fixos chegando mais próximo do fluxo de comércio bilateral efetivo do bloco.

Uma vez definido a método a ser utilizado, o objetivo foi fazer os testes econométricos para verificar se a conduta do método proposto apresenta confiabilidade estatística e relevância. A primeira avaliação foi o teste de Wald modificado para heterocedasticidade groupwise, que neste trabalho indicou a presença de heterocedasticidade [chi2 (8144) = $1.5 \mathrm{e}+08$, Prob $>$ chi $2=0.0000]$. Logo após, foi implementado na equação o teste de autocorrelação (teste de correlação serial de Wooldridge). Este teste indicou a presença de resíduos correlacionados, visto que a hipótese nula foi fortemente rejeitada $[\mathrm{F}(1,8023)$ $=294.516$, Prob $>F=0.0000]$. Nesse sentido, houve a necessidade de usar a opção Huber/White na equação para corrigir tanto o problema de autocorrelação, quanto de heterocedasticidade. Esta opção produz erros padrões corrigidos, visto que existe a opção de relaxar a suposição de independência das observações, mesmo que elas sejam correla- 
cionadas.

Com o objetivo de testar a normalidade dos resíduos, foi aplicado à regressão o teste D'agostino-Pearson, conhecido como o teste D. Esta avaliação verifica se a distribuição dos resíduos da equação possui uma distribuição normal e simétrica. Neste trabalho, esta hipótese foi aceita a 1\% de significância e representados graficamente na figura 3 .

Figura 3 - Distribuição dos resíduos

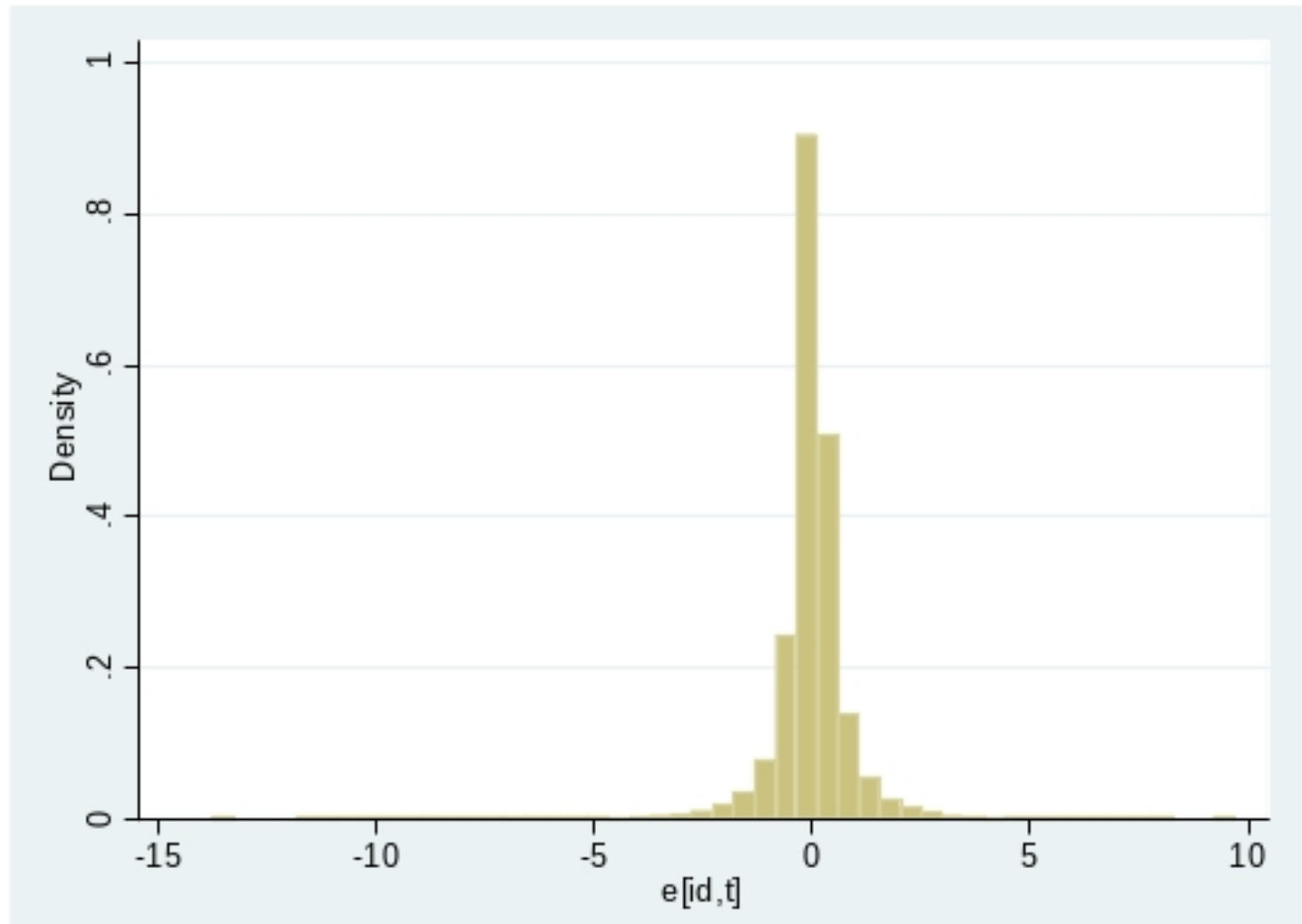

Fonte: Dados do estudo.

\subsection{Resultados sobre o comércio potencial da Aliança do Pacífico}

Os resultados da estimação por efeitos aleatórios e fixos são apresentados na tabela 6 . Apenas os coeficientes do PIB de ambos os países, importador e exportador, e do PIB per capita do exportador foram significativos ao nível de confiança de $90 \%$ na estimação por efeitos fixos, apresentando os sinais esperados.

Os coeficientes da equação estimada por efeitos fixos foram combinados com os dados reais das variáveis de cada membro do bloco para calcular o comércio potencial para todos os fluxos bilaterais dos membros da AP nos anos de 2002 e 2013. Nesse sentido,

Econômica-Niterói, v. 20, n. 2, p. 107-134. Dezembro, 2018 
Tabela 6 - Coeficientes estimados

\begin{tabular}{lcclcc}
\hline Variável & $\begin{array}{c}\text { Coeficiente } \\
\text { efeitos } \\
\text { aleatórios }\end{array}$ & $\begin{array}{c}\text { Coeficiente } \\
\text { efeitos } \\
\text { fixos }\end{array}$ & Variável & $\begin{array}{c}\text { Coeficiente } \\
\text { efeitos } \\
\text { aleatórios }\end{array}$ & $\begin{array}{c}\text { Coeficiente } \\
\text { efeitos } \\
\text { fixos }\end{array}$ \\
\hline i_pib & 1,12 & 0,75 & CAN_imp & N.S.* & - \\
i_pib_cap & $-0,18$ & N.S.* & UE & 0,14 & - \\
j_pib & 1,23 & 1,34 & UE_imp & $-0,22$ & - \\
j_pib_cap & $-0,34$ & $-0,85$ & UE_exp & 0,38 & - \\
Dist_relativa & 0,25 & - & NAFTA & N.S.* & - \\
Distância & 1,19 & - & NAFTA_imp & N.S.* & - \\
i_area & $-0,14$ & - & NAFTA_exp & 0,47 & - \\
j_area & $-0,16$ & - & MERCOSUL & N.S.* & - \\
Adjacência & 0,64 & - & MERCOSUL_imp & N.S.* & - \\
i_litoral & 0,47 & - & MERCOSUL_exp & N.S.* & - \\
j_litoral & N.S.* & - & ASEAN & 1,91 & - \\
Idioma & 0,61 & - & ASEAN_imp & 0,55 & - \\
Colonial & 0,69 & - & ASEAN_exp & 1,42 & - \\
CAN & 0,99 & - & Constante & $-28,2$ & $-27,4$ \\
CAN_exp & 0,53 & - & $R^{2}$ & 0,66 & 0,41 \\
Observações: 94.883 & & & & \\
\hline
\end{tabular}

Fonte: Dados do estudo.

*N.S.: Coeficiente não significativo com nível de confiança de $90 \%$. 
Tabela 7 - Coeficientes estimados

\begin{tabular}{lllll}
\hline Ano & Comércio potencial & Comércio efetivo & Diferença US\$ bilhões & Diferença (\%) \\
\hline 2002 & 6124 & 4711 & 1413 & 29,9 \\
2013 & 20601 & 20842 & -24 & $-1,16$ \\
\hline
\end{tabular}

Fonte: Dados do estudo.

Tabela 8 - Potencial de comércio bilateral em 2002 (US\$ milhões)*

\begin{tabular}{lllll}
\hline Fluxo Bilateral & Previsão & Efetivo & Diferença & Diferença \% \\
\hline Chile & 1125 & 930 & -195 & 20,9 \\
Colômbia & 1342 & 1117 & -225 & 20,1 \\
México & 1900 & 1514 & -386 & 25,4 \\
Peru & 1757 & 1150 & -607 & 50,7 \\
Total & 6124 & 4711 & -1413 & 29,9 \\
\hline
\end{tabular}

Fonte: Dados do estudo.

de acordo com a tabela 7, para o ano de 2002 foi estimado o comércio potencial de US\$ 6,124 bilhões, enquanto que o comércio efetivo foi de US\$ 4,753 bilhões, assim havendo a possibilidade de expansão do comércio em quase $30 \%$. Para o período de 2013 , foi estimado o comércio potencial de US\$20,601 bilhões, enquanto o comércio potencial efetivo foi de US\$20,842, demonstrando que já não havia espaço para aumentar o comércio entre os países do bloco.

Ao se analisar os fluxos totais de comércio por país para o ano de 2002, observase que todos os países da AP apresentavam um potencial de comércio bilateral acima do efetivo. O Peru era o país com maior potencial de comércio a ser explorado entre os países pesquisados, com a possibilidade de aumentar em 50\% o volume de comércio com os outros países, o equivalente a US\$ 607 milhões em (tabela 8). Logo após vinha o México, com um comércio potencial $25 \%$ acima do efetivo, ou US\$ 386 milhões. Colômbia e Chile também mostravam potencial de aumento do comércio com os demais países da AP, em torno de $20 \%$, mas a Colômbia teria um aumento maior em termos absolutos.

Quando se analisa o comércio bilateral por país para o ano de 2002, verifica-se que o México era o aquele que apresentava o maior potencial de expansão do comércio intraAP, tanto de exportações como importações. Não por coincidência, o México apresenta o menor grau de liberalização comercial com os demais países do bloco, especialmente com Colômbia e Peru. O potencial de aumento das exportações do México para o Peru seria o mais significativo, chegando a US\$ 1,309 bilhão, um aumento de quase seis vezes em relação ao comércio efetivo (tabela 9). Em seguida, destaca-se o potencial de crescimento das importações mexicanas do Peru, que se situavam US\$ 541 milhões acima das efetivas.

Em relação à estimação do potencial de comércio para o ano de 2013, de acordo com a tabela 10, observa-se que houve uma redução significativa da diferença em relação ao

Econômica-Niterói, v. 20, n. 2, p. 107-134. Dezembro, 2018 
Tabela 9 - Potencial de comércio bilateral em 2002 por par de países (US\$ milhões)

\begin{tabular}{lllll}
\hline Fluxo Bilateral & Previsão & Efetivo & Diferença & $\begin{array}{l}\text { Margem de } \\
\text { Diferença (\%) }\end{array}$ \\
\hline Chile x Colômbia & 147 & 205 & 58 & $-28,2$ \\
Chile x México & 901 & 474 & -427 & 90 \\
Chile x Peru & 77 & 251 & 174 & $-69,3$ \\
Colômbia x Chile & 71 & 280 & 209 & $-74,6$ \\
Colômbia x México & 1170 & 677 & -493 & 72,8 \\
Colômbia x Peru & 101 & 160 & 59 & $-36,8$ \\
México x Chile & 328 & 1010 & 682 & $-67,5$ \\
México x Colômbia & 879 & 352 & -527 & 149,7 \\
México x Peru & 693 & 152 & -541 & 355,9 \\
Peru x Chile & 47 & 419 & 372 & $-88,7$ \\
Peru x Colômbia & 126 & 456 & 330 & $-72,3$ \\
Peru x México & 1584 & 275 & -1309 & 476 \\
Total & 6124 & 4711 & -1413 & 29,9 \\
\hline
\end{tabular}

Fonte: Dados do estudo.

comércio efetivo, situando-se inclusive 1,2\% abaixo do mesmo. O único país em que o comércio potencial ainda seria superior ao efetivo seria o México, chegando a US\$ 2,573 bilhões, ou 87,7\%, demonstrando que ainda haveria um grande potencial a ser explorado pelos demais países da AP. Chama a atenção que a diferença teria crescido ao longo do período, dado que em 2002 ela se situava em 25,4\%. Por outro lado, os demais países já teriam um comércio efetivo superior ao estimado em 2013. Isto demonstra que os três países já estariam bastante integrados e que o bloco não deverá trazer alterações significativas nos seus fluxos comerciais bilaterais. A diferença mais acentuada entre o fluxo potencial e efetivo ocorreria com a Colômbia, onde o primeiro ficaria 20,3\% abaixo do segundo, ou US\$1,473 bilhão.

Ao se analisar cada fluxo bilateral de comércio separadamente para o ano de 2013, pode-se verificar que o México pode se beneficiar tanto como importador como exportador para os demais países da AP. Dos doze fluxos examinados, o comércio estimado foi superior ao efetivo em apenas quatro deles, todos envolvendo o México como importador ou exportador (ver tabela 11). As importações mexicanas da Colômbia seria o fluxo com o maior potencial de crescimento entre todos os fluxos pesquisados, chegando a US\$ 2,034 bilhões, o equivalente a uma diferença de 223,4\% em relação às importações efetivas. O mesmo se repete quando se analisa as importações do México do Peru, a segunda maior diferença entre fluxo potencial e efetivo da AP, em termos percentuais. Este fluxo apresentou um comércio estimado 154,2\% superior ao efetivo, o equivalente a US\$ 901 milhões.

Em relação a esses dois casos analisados, este quadro pode ser explicado pelo menor 
Tabela 10 - Potencial de comércio bilateral em 2002 por par de países (US\$ milhões)

\begin{tabular}{lllll}
\hline Fluxo Bilateral & Previsão & Efetivo & Diferença & Diferença \% \\
\hline Chile & 5184 & 6021 & -837 & $-13,9$ \\
Colômbia & 5795 & 7268 & -1473 & $-20,3$ \\
México & 5507 & 2934 & 2573 & 87,7 \\
Peru & 4110 & 4613 & -503 & $-10,9$ \\
Total & 20601 & 20842 & $(240.6)$ & $-1,2$ \\
\hline
\end{tabular}

Fonte: Dados do estudo.

*: considera as importações potenciais e efetivas de cada membro da AP dos demais países do bloco.

Tabela 11 - Potencial de comércio bilateral em 2013 por par de países (US\$ milhões)

\begin{tabular}{lccccc}
\hline Fluxo Bilateral & Previsão & Efetivo & Diferença & $\begin{array}{c}\text { Margem de } \\
\text { Diferença (\%) }\end{array}$ & $\begin{array}{c}\text { Grau de } \\
\text { integração (\%) }\end{array}$ \\
\hline Chile x Colômbia & 945 & 1721 & -775 & $-45,1$ & 99 \\
Chile x México & 3762 & 2542 & 1220 & 48 & 99 \\
Chile x Peru & 477 & 1758 & -1280 & $-72,9$ & 93 \\
Colômbia x Chile & 436 & 903 & -467 & $-51,7$ & 99 \\
Colômbia x México & 4756 & 5495 & -739 & $-13,4$ & 92 \\
Colômbia x Peru & 603 & 870 & -266 & $-30,7$ & 100 \\
México x Chile & 1074 & 1438 & -363 & $-25,3$ & 99 \\
México x Colômbia & 2946 & 911 & 2034 & 223,4 & 92 \\
México x Peru & 1487 & 585 & 901 & 154,2 & 83 \\
Peru x Chile & 280 & 1326 & -1045 & $-78,9$ & 93 \\
Peru x Colômbia & 769 & 1468 & -699 & $-47,6$ & 100 \\
Peru x México & 3061 & 1819 & 1241 & 68,3 & 83 \\
Total & 20601 & 20842 & $(240.6)$ & $-1,2$ & \\
\hline
\end{tabular}

Fonte: Dados do estudo. 
grau integração econômica com o México, sendo de $92 \%$ para Colômbia e de $83 \%$ para o Peru1, ambos os países membros da CAN. Isto significa que, com a formação da Aliança do Pacífico e a consequente queda de todas as barreiras tarifárias, haveria um espaço para aumentar o comércio desses países com o México. As importações do Peru provenientes do México também apresentaram uma diferença significativa entre os valores potenciais e efetivos, atingindo 68,3\%, o equivalente a US\$1,24 bilhão.

Em relação aos fluxos de comércio entre Chile e México, as importações chilenas provenientes do país mexicano seriam as mais afetadas, pois apresentaram uma capacidade estimada de ampliação de US\$ 1,22 bilhão. No entanto, a formação da AP poderia não influenciar diretamente a criação de comércio entre os dois países, visto que eles já são signatários de um tratado de livre comércio vigente desde 1999. Uma das possíveis explicações seria o fato de que o México sofra uma forte concorrência de outros países concorrentes na exportação de produtos industrializados para o Chile. De fato, o Chile possui um alto grau de integração na economia mundial, tendo firmado vários acordos preferenciais de comércio com seus principais parceiros comerciais nas últimas décadas.

Embora o comércio estimado total entre os membros seja praticamente idêntico ao efetivo em 2013, este estudo mostrou que o fluxo potencial de cada par de países apresentou diferenças importantes na maioria dos casos. Dos doze fluxos estudados, o comércio efetivo foi superior ao estimado em oito deles, sinalizando que haveria pouco espaço para um aumento dos fluxos comerciais entre os membros da AP. Deste modo, somente em alguns fluxos, haveria a possibilidade de incrementar o comércio substancialmente com a formação da AP, especialmente o comércio envolvendo o México. Por outro lado, o modelo não conseguiu identificar espaço para o avanço do comércio de Chile, Colômbia e Peru no âmbito da AP, pois os valores estimados ficaram abaixo do efetivo. Portanto, os resultados deste trabalho indicam que o México seria o único beneficiado com a criação da Aliança do Pacífico em termos de expansão de comércio.

Como pode ser observado, no ano de 2002, havia um espaço significativo para aumentar as transações comerciais, pois o comércio potencial estava quase $30 \%$ acima do comércio efetivo. No entanto, em 2013, houve uma convergência entre o comércio efetivo e potencial. Deste modo, é possível interpretar esta convergência entre os fluxos estimados e efetivos, ao longo do período analisado, como resultado da maior liberalização comercial dos países da AP mesmo antes da criação formal do bloco, por meio de acordos comerciais, no âmbito da ALADI, CAN e TLC México-Chile. Nesse sentido, dada a prévia integração comercial entre seus membros, a formalização da Aliança do Pacífico não teria efeitos significativos em termos de ampliação do comércio. Por outro lado, ao analisar os fluxos por par de países, a conclusão que se chega é que o México seria o maior beneficiado com a criação do bloco, demonstrando ainda haver espaço para incrementar suas trocas comerciais. O potencial de aumento do comércio seria maior justamente com Peru e Colômbia, países com os quais o México apresenta um menor grau de integração comercial. 
Os resultados deste artigo são similares em relação às estimações realizadas por Graff e Azevedo (2013) e Papazoglou (2007). Para os primeiros, assim como mostrou esse estudo, houve uma aproximação significativa entre os fluxos estimados e os efetivos, com um diferencial do comércio potencial de apenas 3,47\% acima do efetivo. Além disso, também houve disparidades significativas nos fluxos comerciais entre os pares de países. Os fluxos que apresentaram maior potencial foram Argentina e Paraguai e Argentina e Uruguai, enquanto o Brasil foi o país em que o comércio efetivo mais superou o fluxo potencial. Em relação ao trabalho de Papazoglou (2007), com a entrada da Grécia na União Europeia, havia uma expectativa de convergência das estruturas produtivas gregas em relação à UE. Entretanto, a tendência dos fluxos bilaterais de comércio mostrou o contrário. Os resultados mostraram que as exportações gregas efetivas ficaram abaixo do potencial, enquanto que as importações reais ficaram acima do potencial. Enfim, houve um pequeno potencial de aumento das importações para a Grécia nos anos de 1993 e 1998, enquanto que o comércio efetivo ficou acima do potencial para o ano de 2002.

\section{Considerações finais}

Os quatro países da AP já possuem um viés de integração comercial significativo com o resto do mundo e um nível de tarifas zeradas superior a $90 \%$ entre os próprios integrantes do bloco. Nesse sentido, uma questão relevante está relacionada aos benefícios que a formação do bloco iria trazer em termos de ampliação do comércio entre seus membros. Deste modo, esse trabalho estimou um modelo gravitacional de comércio, usando dados em painel com efeitos fixos, que cobriu os fluxos de comércio dos membros da Aliança do Pacífico, assim como das 98 maiores economias do mundo, no período de 2002 a 2013. Em seguida, os coeficientes estimados, que descrevem os principais determinantes do padrão de comércio dos países da amostra, foram aplicados para os membros do bloco estudado com o objetivo de identificar o comércio potencial para o ano de $2013 \mathrm{e}$ comparando com o ano de 2002.

Os resultados mostraram que o comércio estimado para o ano de 2013 ficou apenas $1 \%$ abaixo do comércio efetivo, o equivalente a US\$240,6 milhões. Deste modo, este trabalho observou que as políticas integracionistas realizadas nas últimas décadas entre os países tiveram o efeito esperado e que a formação da AP não traria um aumento significativo de comércio. Como visto, no ano de 2002, o comércio potencial era quase $30 \%$ superior em relação ao comércio efetivo, não obstante, 11 anos depois, este estudo mostrou que o comércio real e o estimado se tornaram praticamente idênticos. O México, o menos integrado em relação aos demais países da AP, seria o país que mais se beneficiaria com a formação do bloco, tanto como exportador quanto importador.

Os resultados apresentados deste trabalho são similares às estimações realizadas por Graff e Azevedo (2013), onde houve uma aproximação significativa entre os fluxos estimados e os efetivos e também mostrou disparidades significativas nos fluxos comerciais

Econômica-Niterói, v. 20, n. 2, p. 107-134. Dezembro, 2018 
entre os pares de países. Em relação ao trabalho de Papazoglou (2007), com a entrada da Grécia na União Europeia, as estimações mostraram que as exportações gregas efetivas ficaram abaixo do potencial, enquanto as importações reais ficaram acima do potencial, mas com o comércio efetivo ficando acima do potencial para o último ano da análise. Portanto, este estudo conclui que devido à elevada integração comercial já existente entre seus membros antes da formação da AP, o bloco não deverá ampliar os fluxos comerciais de forma significativa entre seus membros. Não obstante, na análise por par de países, o mais beneficiado com a criação da Aliança seria o México, expandindo consideravelmente suas importações e exportações.

\begin{abstract}
From the 1990s, there was a proliferation of Preferential Trade Agreements (APC) around the world. Within this world trade change of scenery, Latin America was a key player in the creation of new agreements. However, due to historical political and economic instability in the region, there has never been a complete integration, mainly due to the protectionist nature of countries. In this sense, the Pacific Alliance, formed by Chile, Colombia, Peru and Mexico comes with a proposal for a different economic integration, aiming to unite their economies further and be open to trade negotiations with third countries. The aim of this study is to estimate and compare the bilateral trade potential between the member countries of the Pacific Alliance (PA), using a gravitational trade model based on a panel data with fixed effects for years 2002 and 2013, with a sample of 98 countries. The results showed that the estimated trade for 2002 was $30 \%$ above the actual trade, showing a trade potential to be explored. However, in 2013 the estimated trade was already $1.2 \%$ below the actual trade. It seems that the trade liberalization of the PA members, that occurred prior to the block's formation, contributed to the convergence of the actual and potential trade.
\end{abstract}

Keywords: Bilateral trade flow, gravity model, Pacific Alliance.

JEL: F15; F14; C68.

\title{
Referências bibliográficas
}

AMSDEN, A. The directionality of trade: historical perspective and overview. In: HAVRYLYSHYN, O. (Ed.). Exports of developing countries: how direction affects performance - a World Bank symposium. The World Bank, 1987. p. 123-138.

Disponível em: <http://documents.worldbank.org/curated/en/968061468740975942/

Exports-of-developing-countries-how-direction-affects-performance-a-World-Bank-symposium>.

ANALDEX. Boletin Quincenal de Comercio Exterior. Bogotá, Colômbia: Analdex, v. 318, julho 2014. 
ANDERSON, J.; WINCOOP, E. V. Gravity with gravitas: A solution to the border puzzle. American Economic Review, v. 93, n. 1, p. 170-192, 2003. Disponível em: <https://EconPapers.repec.org/RePEc:aea:aecrev:v:93:y:2003:i:1:p:170-192>.

AREND, M. 50 anos de industrialização do brasil (1955-2005): uma análise evolucionária. 2009.

AREND, M. A industrialização do Brasil ante a nova divisão internacional do trabalho. [S.1.], 2015.

BACHA, E. Bonança externa e desindustrialização no brasil: uma análise do período 2005-2011. O futuro da indústria no Brasil. Desindustrialização em debate. Rio de Janeiro: Civilização Brasileira, 2013.

BERGSTRAND, J. The gravity equation in international trade: Some microeconomic foundations and empirical evidence. The Review of Economics and Statistics, v. 67, n. 3, p. 474-81, 1985. Disponível em: <https://EconPapers.repec.org/RePEc:tpr:restat:v:67:y: 1985:i:3:p:474-81>.

BERGSTRAND, J.; EGGER, P.; LARCH, M. Gravity redux: Estimation of gravityequation coefficients, elasticities of substitution, and general equilibrium comparative statics under asymmetric bilateral trade costs. Journal of International Economics, v. 89, n. 1, p. 110-121, 2013. Disponível em: <https://EconPapers.repec.org/RePEc:eee: inecon:v:89:y:2013:i:1:p:110-121>.

BERTOLLI, S.; MEDEIROS, N. H. Evolução da competitividade da indústria brasileira: uma análise a partir do movimento de reestruturação setorial nos anos 90. ENCONTRO SOBER, v. 48, p. 1995-96, 2003.

BHAGWATI, J.; PANAGARIYA, A. Preferential trade areas and multilateralism: strangers, friends or foes? In: BHAGWATI, J.; PANAGARIYA, A. (Ed.). The Economics of Preferential Trade Agreements. [S.1.]: AEI Press, Washington, DC, 1996. p. 1-78.

BIRD. Trade blocs. A World Bank Policy Research Report, Banco Mundial, 2000. Disponível em: <http://documents.worldbank.org/curated/en/487761468765040468/ Trade-blocs $>$.

BIRD. Countries and economies. Banco Mundial, 2015. [Online; acesso 04-Abril-2015]. Disponível em: <http://data.worldbank.org/country>.

BONELLI, R.; PESSOA, S.; MATOS, S. Desindustrialização no brasil: fatos e interpretação. O futuro da indústria no Brasil: desindustrialização em debate. Rio de Janeiro: Civilização Brasileira, p. 201-225, 2013.

CAMERON, C.; TRIVEDI, P. Microeconometrics using STATA. [S.1.]: College Station: Stata Press, 2009. 
CANO, W. Soberanía e política económica en américa latina. São Paulo: UNESP., v. 1, 2000.

CANO, W. A desindustrialização no brasil. in: Texto para discussão. Instituto de Economia/Unicamp, n. 200, 2012.

CANO, W.; SILVA, A. L. G. Política industrial do governo lula. MAGALHÃES et al. Os, 2010.

CARNEIRO, R. Desenvolvimento em crise: a economia brasileira no último quarto do século XX. [S.1.]: Unesp, 2002.

CARVALHO, L.; KUPFER, D. et al. A transição estrutural da indústria brasileira: da diversificação para a especialização. Anais do XXXV Encontro Nacional de Economia da ANPEC, 2007.

CASTRO, L. B. d. Privatização, abertura e desindexação: a primeira metade dos anos 90. Economia brasileira contemporânea. Rio de Janeiro: Elsevier, p. 142-165, 2005.

CEPII. The GeoDist database. CENTRE D'ESTUDES PROSPECTIVES ET D'INTERTIONALES DISTANCES, 2015. Disponível em: <http://www.cepii.fr/CEPII/ en/bdd $\_$modele/presentation.asp?id=6>.

CHEONG, D.; HAMANAKA, S.; PLUMMER, M. Methodology for impact assessment of free trade agreements. Filipinas: Asian Development Bank, 2010. Disponível em: $<$ https://think-asia.org/handle/11540/134>.

FEIJÓ, C.; CARVALHO, P. G. M.; ALMEIDA, J. S. G. d. Ocorreu desindustrialização no brasil? Documento do Instituto para o Desenvolvimento Industrial (IEDI), 2005.

FEIJÓ, C.; CARVALHO, P. G. M. d. A evolução da estrutura industrial. Documento do Instituto para o Desenvolvimento Industrial (IEDI), 2008.

FILHO, R. S. Uma perspectiva schumpeteriana/estruturalista do padrão de competitividade internacional brasileiro: 1985-2007. 2011.

INTAL. Aliança do Pacífico e do MERCOSUL: perfis de comércio. BID, 2014. [Online; accesso 16-Set-2014]. Disponível em: <http://publications.iadb.org/handle/11319/6565? locale-attribute $=\mathrm{pt}>$.

LACERDA, A. C.; OTHER. Economia brasileira. ed. São Paulo: Saraiva, v. 4, 2000.

LAMONICA, M. T.; FEIJÓ, C. A. d. Crescimento e industrialização no brasil: uma interpretação à luz das propostas de kaldor. Brazilian Journal of Political Economy, SciELO Brasil, v. 31, n. 1, p. 118-138, 2011. 
MARQUETTI, A. A. Progresso técnico, distribuição e crescimento na economia brasileira: 1955-1998. Estudos Econômicos (São Paulo), v. 32, n. 1, p. 103-124, 2002.

MOREIRA, M. M. A indústria brasileira nos anos 90: O que já se pode dizer? Banco Nacional de Desenvolvimento Econômico e Social, 1999.

NEGRI, F. D.; ALVARENGA, G. V. A primarização da pauta de exportações no brasil: ainda um dilema. Radar Tecnologia, Produção e Comércio Exterior, v. 13, p. 7-14, 2011.

OREIRO, J. L.; FEIJÓ, C. A. Desindustrialização: conceituação, causas, efeitos e o caso brasileiro. Brazilian Journal of Political Economy, SciELO Brasil, v. 30, n. 2, p. 219-232, 2010.

PEREIRA, L. C. B.; MARCONI, N. Existe doença holandesa no brasil? Fórum de Economia da Fundação Getúlio Vargas, v. 4, 2007.

ROWTHORN, R.; RAMASWAMY, R. Growth, trade, and deindustrialization. IMF Staff papers, Springer, v. 46, n. 1, p. 18-41, 1999.

TREGENNA, F. Characterising deindustrialisation: An analysis of changes in manufacturing employment and output internationally. Cambridge Journal of Economics, Oxford University Press, v. 33, n. 3, p. 433-466, 2008.

VERSIANI, F.; SUZIGAN, W. O processo brasileiro de industrialização: uma visão geral. In: Congresso Internacional de História Econômica. [S.l.: s.n.], 1990. v. 10.

WATANABE, M. Indústria de média-alta tecnologia puxa déficit. Jornal Valor Econômico, 2012. 